(2) Open Access Full Text Article

\title{
Analysis of the Risk Factors for Hypotension in Laparoscopic Hiatal Hernia Repair
}

\author{
Ya-Nan Jin \\ Hao Feng \\ Zhen-Yuan Wang \\ Jie Li
}

Department of Anesthesiology, Beijing Chao-Yang Hospital, Capital Medical University, Beijing, People's Republic of China
Correspondence: Jie Li

Department of Anesthesiology, Beijing

Chao-Yang Hospital, Capital Medical

University, Beijing, People's Republic of

China

Tel +86 I362/288322

$\mathrm{Fax}+861051718475$

Email lijie1988@email.cn
Objective: This study aimed to investigate the risk factors for hypotension in patients undergoing laparoscopic hiatal hernia repair.

Methods: The clinical data of patients who underwent laparoscopic repair of a hiatal hernia in the Beijing Chao-Yang Hospital of Capital Medical University between February 2018 and January 2021 were retrospectively collected, and their perioperative data were obtained by querying the electronic medical record system. The patients were divided into two groups - a hypotension group and a normal group-based on the occurrence of intraoperative hypotension, which was defined as a mean arterial pressure $<65 \mathrm{mmHg}$ and lasting $\geq 1$ minute during the operation. The variables with a $P$ value $\leq 0.1$ in univariate regression analysis and clinically considered relevant variables were included in multivariate regression analysis in order to screen the risk factors for hypotension in these patients.

Results: A total of 114 patients were included in the analysis. The incidence of hypotension was $54.4 \%$. Old age was identified as the only risk factor for hypotension during hiatal hernia surgery.

Conclusion: Old age is the only risk factor for intraoperative hypotension in patients undergoing laparoscopic hiatal hernia repair.

Keywords: hiatal hernia, hypotension, risk factors

\section{Introduction}

Laparoscopic repair is an effective method of treating a hiatal hernia. ${ }^{1-3}$ However, it has been reported that pneumothorax caused by pleural injury during laparoscopic hiatal hernia repair may cause hypotension, ${ }^{4}$ while the incidence of hypotension in hiatal hernia repair in the absence of pneumothorax is rarely reported. It is known that intraoperative hypotension is related to myocardial injury, acute kidney injury, and death, with the risk increasing as the blood pressure lowers. ${ }^{5}$ The present retrospective study aimed to observe the incidence of intraoperative hypotension in patients with hiatal hernia and explore the risk factors for intraoperative hypotension in order to provide a decision basis for clinical treatment.

\section{Materials and Methods}

\section{Subjects}

The clinical data of patients who underwent laparoscopic repair of a hiatal hernia in the Beijing Chaoyang Hospital of Capital Medical University between February 2018 and January 2021 were retrospectively collected. 


\section{Exclusion Criteria}

(1) pneumothorax occurred during operation; (2) patient was moved to open surgery during operation; (3) patient underwent further operations.

The study was conducted with approval from the Ethics Committee of Beijing Chaoyang Hospital of Capital Medical University (No: 2020-Ke-289). This study was conducted in accordance with the declaration of Helsinki. Written informed consent was obtained from all participants.

\section{Operational Procedure}

After general anesthesia via endotracheal intubation, artificial pneumoperitoneum was established, the posterior window of the esophageal hiatus was completely released, and the distal esophagus was restored to the abdominal cavity by at least $3 \mathrm{~cm}$. Based on the size of the hiatus defect, a V-Loc suture was used to narrow the hiatus, after which the sutured site was intermittently strengthened using a $2 / 0$ prolene suture, ensuring the hiatus passed through the esophagus only. (This degree of tightness was chosen because it allowed for the insertion of forceps.) An $8 \times 8 \mathrm{~cm}$ composite-mesh anti-adhesion patch (Medtronic, Covidien, Parietex ${ }^{\mathrm{TM}}$ ) was then fixed to both diaphragmatic feet with an absorbable-nail gun, and the upper part was fixed with Kangpaite medical glue. The greater curvature of the stomach, esophagus, and diaphragm were sutured with four stitches using a $2 / 0$ prolene suture to form a fundoplication (Dor, $180^{\circ}$ ). After the operation, a drainage tube was placed from the trocar port.

All operations were performed under a laparoscope by Huiqi Yang, the chief surgeon of Hernia and Abdominal Wall Surgery, Beijing Chao-Yang Hospital of Capital Medical University, and the same team of doctors.

\section{Subject Grouping and Observation Indexes}

The patients were divided into two groups-a hypotension group and a normal group — based on the occurrence of intraoperative hypotension, which was defined as a mean arterial pressure (MAP) $<65 \mathrm{mmHg}$ lasting $\geq$ 1 minute after the posterior window of the esophageal hiatus was released. ${ }^{5}$ The perioperative data, which were collected by querying the electronic medical record system, included gender, age, height, weight, American Society of Anesthesiologists (ASA) grade, hiatal hernia classification, hiatal hernia size, hypertension, coronary heart disease, diabetes, stroke, respiratory system diseases, fasting time before anesthesia, basal blood pressure, and preoperative heart rate. The intraoperative data that were collected included the presence of intraoperative hypotension and its duration, vasoactive drug use and types, volume and type of fluid supplement before hernia sac opening, and intraoperative fluid supplement volume.

\section{Statistical Analysis}

Data were analyzed using statistical software SPSS 22.0. Measurement data were expressed as mean \pm standard deviation $(\mathrm{x} \pm \mathrm{SD})$, and comparison between two groups was undertaken using an independent sample $t$-test. Count data were expressed as a percentage (\%) and compared using a $\chi^{2}$ test. Logistic regression analysis was performed to identify the risk factors for intraoperative hypotension, after which the variables with a $P$ value $\leq 0.1$ in univariate regression analysis and the variables clinically considered relevant were included in multivariate regression analysis. $P<0.05$ was considered statistically significant.

\section{Results}

\section{General Characteristics}

A total of 114 patients were included in the study, 62 of which had intraoperative hypotension (hypotension group) and 52 of which had no intraoperative hypotension (normal group); the incidence of hypotension was $54.4 \%$. The baseline data of the two groups of patients are shown in Table 1.

Compared with the normal group, the mean age of patients in the hypotension group was significantly higher $(65.4 \pm 11.1$ years vs $55.8 \pm 13.9$ years; $P<0.001)$, the height was significantly lower $(159.4 \pm 9.4 \mathrm{~cm}$ vs $164.3 \pm$ $10.4 \mathrm{~cm} ; P=0.008)$, and the body weight was significantly lower $(64.4 \pm 12.0 \mathrm{~kg}$ vs $69.3 \pm 12.1 \mathrm{~kg} ; P=0.047)$, but there was no significant difference in body mass index (BMI) between the two groups $\left(25.2 \pm 3.6 \mathrm{~kg} / \mathrm{m}^{2}\right.$ vs 25.5 $\left.\pm 2.8 \mathrm{~kg} / \mathrm{m}^{2} ; P=0.74\right)$. Preoperative ejection fraction in both groups were: normal group $(59.7 \pm 2.1) \%$, hypotension group $(57.3 \pm 1.8) \%, \mathrm{p}=0.16$. Neither group had heart valve disease before surgery. The hypotension group also had a significantly higher preoperative baseline systolic blood pressure $(153.9 \pm 20.1 \mathrm{mmHg}$ vs $144.0 \pm 13.6 \mathrm{mmHg} ; P=$ $0.003)$ and a significantly higher proportion of patients with preoperative hypertension $(32.3 \%$ vs $15.4 \%$; $P=$ 0.04). There were no significant differences between the 
Table I The Baseline Data of the Two Groups of Patients

\begin{tabular}{|c|c|c|c|}
\hline Items & Normal Group $(n=52)$ & Hypotension Group $(n=62)$ & $P$ value \\
\hline Age (year) & $55.8 \pm 13.9$ & $65.4 \pm 11.1$ & $<0.001$ \\
\hline Gender, Male (\%) & $26(50 \%)$ & $22(35 \%)$ & 0.12 \\
\hline Height (cm) & $164.3 \pm 10.4$ & $159.4 \pm 9.4$ & 0.008 \\
\hline Weight (kg) & $69.3 \pm 12.1$ & $64.4 \pm 12.0$ & 0.047 \\
\hline BMI $\left(\mathrm{kg} / \mathrm{m}^{2}\right)$ & $25.5 \pm 2.8$ & $25.2 \pm 3.6$ & 0.74 \\
\hline ASA grade & $1.9 \pm 0.5$ & $2.0 \pm 0.5$ & 0.15 \\
\hline Ejection fraction & $(59.7 \pm 2.1) \%$ & $(57.3 \pm 1.8) \%$ & 0.16 \\
\hline Maximum length of hernia $(\mathrm{cm})$ & $5.6 \pm 1.3$ & $5.7 \pm 1.5$ & 0.60 \\
\hline Maximum width of hernia $(\mathrm{cm})$ & $4.1 \pm 1.0$ & $4.3 \pm 1.2$ & 0.47 \\
\hline Maximum cross sectional area of hernia $\left(\mathrm{cm}^{2}\right)$ & $23.7 \pm 10.6$ & $26.1 \pm 13.7$ & 0.48 \\
\hline Types of hernia $[n(\%)]$ & & & 0.99 \\
\hline Type I & $12(23.1 \%)$ & $16(25.8 \%)$ & \\
\hline Type II & $15(28.8 \%)$ & $18(29.0 \%)$ & \\
\hline Type III & $17(32.7 \%)$ & $19(30.6 \%)$ & \\
\hline Type IV & $8(15.4 \%)$ & $9(14.5 \%)$ & \\
\hline Preoperative water fasting (hour) & $\mid 2.1 \pm 1.7$ & $11.8 \pm 1.6$ & 0.34 \\
\hline Systolic blood pressure & $144.0 \pm 13.6$ & $153.9 \pm 20.1$ & 0.003 \\
\hline Diastolic blood pressure & $84.6 \pm 9.8$ & $84.5 \pm 10.3$ & 0.99 \\
\hline Heart rate & $78 \pm 13$ & $79 \pm 13$ & 0.36 \\
\hline Hypertension[n(\%)] & $8(15.4 \%)$ & $20(32.3 \%)$ & 0.04 \\
\hline Coronary heart disease $[\mathrm{n}(\%)]$ & $3(5.8 \%)$ & $9(14.5 \%)$ & 0.13 \\
\hline Diabetes $[n(\%)]$ & $2(3.8 \%)$ & $7(11.3 \%)$ & 0.18 \\
\hline Stroke $[n(\%)]$ & $5(9.6 \%)$ & $10(16.1 \%)$ & 0.31 \\
\hline Chronic obstructive pulmonary disease $[n(\%)]$ & $5(9.6 \%)$ & $7(11.3 \%)$ & 0.77 \\
\hline Sleep apnea syndrome $[n(\%)]$ & $3(5.8 \%)$ & $2(3.2 \%)$ & 0.66 \\
\hline
\end{tabular}

two groups in ASA grade, type and size of hiatal hernia, and other complications.

\section{Intraoperative Conditions}

The intraoperative conditions of the two groups are shown in Table 2. The mean duration of intraoperative hypotension in the hypotension group was $20 \pm 15$ minutes. Compared with the normal group, the proportions of patients in the hypotension group who intraoperatively received dopamine $(12.9 \%$ vs $1.9 \% ; P=0.04)$, metaraminol (16.1\% vs $1.9 \% ; P=0.01)$, norepinephrine $(22.6 \%$ vs $0 \% ; P<0.001)$, and ephedrine $(12.9 \%$ vs $0 \% ; P=0.008)$ were significantly higher. There were no differences between the two groups in the amount of preoperative rehydration, types of rehydration, intraoperative blood loss, and intraoperative rehydration.

\section{Risk Factors}

The results of the regression analysis are shown in Table 3. Univariate regression analysis revealed that old age, high basal systolic blood pressure, and hypertension were risk factors for hypotension during hiatal hernia surgery. These three variables, the maximum cross-sectional area of the hiatal hernia, and operation time were included in the multivariate regression analysis, the results of which revealed that old age was the only risk factor for hypotension during hiatal hernia surgery $(\mathrm{OR}=1.05, P=0.01)$.

\section{Discussion}

Hiatal hernia $(\mathrm{HH})$ occurs when the stability of the esophagogastric junction is impaired, allowing upward dislocation of the lower esophageal sphincter and a part of the stomach through the crural diaphragm. $\mathrm{HH}$ is associated with gastroesophageal reflux disease, which seriously reduces the patient's quality of life. ${ }^{6}$ It may even prevent obese patients from having bariatric surgery, because the common surgery such as sleeve gastrectomy, Roux-en-Y gastric bypass and one anastomosis gastric bypass may increase the risk of reflux. ${ }^{7,8}$ Laparoscopic repair is an effective method of treating a hiatal hernia. 
Table 2 The Intraoperative Conditions of the Two Groups

\begin{tabular}{|c|c|c|c|}
\hline Items & Normal Group(n=52) & Hypotension Group $(n=62)$ & $P$ value \\
\hline Types of rehydration & & & 0.18 \\
\hline Voluven & $4 \mathrm{I}(78.8 \%)$ & $42(67.7 \%)$ & \\
\hline Ringer's solution & $\mathrm{II}(2 \mathrm{I} .2 \%)$ & $20(32.3 \%)$ & \\
\hline Amount of preoperative rehydration $(\mathrm{mL})$ & $483 \pm 58$ & $490 \pm 44$ & 0.53 \\
\hline Operation time (min) & $102.1 \pm 29.7$ & $109.6 \pm 40.0$ & 0.77 \\
\hline Intraoperative blood loss (mL) & $8 \pm 7$ & $8 \pm 3$ & 0.21 \\
\hline Intraoperative rehydration $(\mathrm{mL})$ & $1203 \pm 318$ & $1276 \pm 300$ & 0.33 \\
\hline Duration of intraoperative hypotension (min) & 0 & $20 \pm 15$ & $<0.001$ \\
\hline \multicolumn{4}{|l|}{ Application of positive inotropic drugs (n) } \\
\hline Dopamine & $\mathrm{I}(\mathrm{I} .9 \%)$ & $8(12.9 \%)$ & 0.04 \\
\hline Metaraminol & $\mathrm{I}(\mathrm{I} .9 \%)$ & $10(16.1 \%)$ & 0.01 \\
\hline Norepinephrine & 0 & $14(22.6 \%)$ & $<0.001$ \\
\hline Adrenaline & 0 & $\mathrm{I}(\mathrm{I} .6 \%)$ & 1.00 \\
\hline Ephedrine & 0 & $8(12.9 \%)$ & 0.008 \\
\hline
\end{tabular}

In this study, the incidence of hypotension in 114 patients undergoing hiatal hernia repair was retrospectively analyzed. The main findings of the study were that the incidence of hypotension in laparoscopic hiatal hernia repair was $54.4 \%$ and that old age was the only independent risk factor for intraoperative hypotension in these patients.

The present study represents the largest sample size for the incidence of hypotension during laparoscopic hiatal hernia repair so far. Previous literature offers no report on the incidence of intraoperative hypotension in patients undergoing hiatal hernia repair, although Srivastava et al analyzed the risk factors for hypotension during laparoscopic surgery. ${ }^{9}$ Phillips et al reported that the incidence of tension pneumothorax in laparoscopic hiatal hernia repair was $22 \%$ and that the probability of hypotension caused by tension pneumothorax was $91 \%{ }^{4}$ The sample size used by Phillips et al, however, was only 50 cases, which is

Table 3 The Results of the Regression Analysis

\begin{tabular}{|c|c|c|c|c|}
\hline \multirow[t]{2}{*}{ Items } & \multicolumn{2}{|c|}{ Single Factor Regression Analysis } & \multicolumn{2}{|c|}{ Multivariate Regression Analysis } \\
\hline & $95 \% \mathrm{Cl}$ & P value & $95 \% \mathrm{Cl}$ & P value \\
\hline Age & $1.07(1.03,1.10)$ & $<0.001$ & $1.05(1.01,1.09)$ & 0.01 \\
\hline BMI & $0.97(0.87,1.09)$ & 0.63 & & \\
\hline ASA grade & $\mathrm{I} .78(0.8 \mathrm{I}, 3.9 \mathrm{I})$ & 0.15 & & \\
\hline Maximum cross sectional area of hernia & $1.02(0.99,1.05)$ & 0.30 & $1.01(0.97,1.04)$ & 0.76 \\
\hline Types of hernia & $0.94(0.65,1.35)$ & 0.73 & & \\
\hline Preoperative water fasting & $0.91(0.73,1.14)$ & 0.42 & & \\
\hline Systolic blood pressure & $1.03(1.01,1.06)$ & 0.005 & $1.02(0.99,1.05)$ & 0.16 \\
\hline Diastolic blood pressure & $0.99(0.96,1.04)$ & 0.95 & & \\
\hline Heart rate & $1.01(0.98,1.04)$ & 0.49 & & \\
\hline Hypertension & $2.62(1.04,6.59)$ & 0.04 & $1.68(0.57,4.93)$ & 0.35 \\
\hline Coronary heart disease & $2.77(0.7 \mathrm{I}, \mathrm{I} 0.84)$ & 0.14 & & \\
\hline Diabetes & $3.18(0.63,16.04)$ & 0.16 & & \\
\hline Stroke & $\mathrm{I} .8 \mathrm{I}(0.58,5.67)$ & 0.31 & & \\
\hline Chronic obstructive pulmonary disease & $1.20(0.36,4.02)$ & 0.77 & & \\
\hline Sleep apnea syndrome & $0.54(0.09,3.39)$ & 0.52 & & \\
\hline Operation time & I.0I $(0.99,1.02)$ & 0.27 & I.0I $(0.99,1.02)$ & 0.39 \\
\hline Intraoperative blood loss & $\mathrm{I} .00(0.93, \mathrm{I} .07)$ & 0.98 & & \\
\hline
\end{tabular}


relatively small in comparison with the sample size of the present study; all the operations in the present study were also performed by the same surgeons, leading to higher consistency and representativeness.

This study found that by adjusting for age, gender, BMI, ASA grade, hernia size and type, fasting time, basic blood pressure, combined with chronic diseases, operation time, intraoperative blood loss and other factors, old age was the independent risk factor of hypotension in laparoscopic hiatal hernia repair. Kazakova et al found that cardiovascular disease increases the risk of cardiovascular accident during surgery, ${ }^{10}$ and elderly patients are at higher risk of cardiovascular disease. Kudsi et al proposed that an increase in age increases the risk of complications and surgical complications. ${ }^{11}$ Wang et al proposed that some degree of peripheral arteriosclerosis or changes of peripheral vascular elasticity caused by diabetes mellitus are common in elderly patients, ${ }^{12}$ while peripheral vascular disease has been shown to be a risk factor for intraoperative hypotension. In the present study, although chronic disease was not a risk factor, the findings of Kazakova et $\mathrm{al}^{10}$ may explain why old age is a risk factor for intraoperative hypotension. As patients age, their diaphragm contraction and lung function decrease, which may contribute to intraoperative hypotension in elderly patients. However, their correlation needs to be further demonstrated by prospective studies with a larger sample size and basic studies.

About a third of general anesthesia patients have hypotension after anesthesia induction and before skin incision. ${ }^{4,13,14}$ Therefore, in order to eliminate the interference of anesthesia factors as far as possible, the occurrence of hypotension was observed in the present study from when the posterior window of the esophageal hiatus was released. Brown reported that the establishment of pneumoperitoneum in laparoscopic surgery led to the compression of the inferior vena cava and the reduction of venous return, which reduced cardiac preload and cardiac output and resulted in a lowering of blood pressure. ${ }^{15}$ Sharma et al found that positive pressure ventilation, a dorsal elevated position, anesthetic drugs, and preoperative water fasting could also reduce venous return, resulting in the occurrence of intraoperative hypotension. ${ }^{16}$ In the present study, all operations were performed by the same surgeon, all patients were placed in the supine position with a head height of $30^{\circ}$, the pneumoperitoneum pressure was $14 \mathrm{mmHg}$ for all, and there were no significant differences in fasting time, operation time, anesthesia mode, and intraoperative fluid volume between the two groups.

Previous studies have reported that intraoperative hypotension is closely related to many adverse outcomes, including myocardial injury, ${ }^{17}$ acute kidney injury, ${ }^{18}$ a higher probability of postoperative cognitive impairment, ${ }^{19}$ prolonged hospital stays, and increased risk of postoperative death $;{ }^{20}$ one study also found that the risk of these adverse outcomes increased as the blood pressure decreased and operation time increased. ${ }^{21}$ Therefore, analyzing the occurrence of intraoperative hypotension and its risk factors will allow clinicians to more effectively reduce the incidence of adverse outcomes of surgical anesthesia.

\section{The Present Study Had Some Limitations}

It was a retrospective study, and, although representing the largest sample size in the research field to date, the sample was relatively small; furthermore, the effect of intraoperative hypotension on postoperative recovery was not analyzed. The conclusion of the study therefore needs to be verified by large-sample randomized controlled trials.

\section{Conclusion}

The incidence of hypotension in laparoscopic hiatal hernia repair was $54.4 \%$, and old age was the only independent risk factor for intraoperative hypotension in these patients. Age-related declines in cardiopulmonary function may be involved, but further research is needed to confirm this.

\section{Ethics Approval and Consent to Participate}

This study was conducted with approval from the Ethics Committee of Beijing Chaoyang Hospital of Capital Medical University (No: 2020-Ke-289). This study was conducted in accordance with the declaration of Helsinki. Written informed consent was obtained from all participants.

\section{Funding}

There is no funding to report.

\section{Disclosure}

The authors declare that they have no competing interests. 


\section{References}

1. Wu JS, Dunnegan DL, Soper NJ. Clinical and radiologic assessment of laparoscopic paraesophageal hernia repair. Surg Endosc. 1999;13 (5):497-502. doi:10.1007/s004649901021

2. Yuan X, Yang H, Nie Y, Guan L, Chen J. The laparoscopic repair of giant diaphragmatic hernia with synthetic mesh: a report of three cases. Int J Abdom Wall Hernia Surg. 2021;4:31-34.

3. Inaba CS, Oelschlager BK, Yates RB, et al. Characteristics and outcomes of patients undergoing paraesophageal hernia repair with selective use of biologic mesh. Surg Endosc. 2021. doi:10.1007/ s00464-021-08399-w

4. Phillips S, Falk GL. Surgical tension pneumothorax during laparoscopic repair of massive hiatus hernia: a different situation requiring different management. Anaesth Intensive Care. 2011;39 (6):1120-1123. doi:10.1177/0310057X1103900621

5. Wijnberge M, Geerts BF, Hol L, et al. Effect of a machine learning-derived early warning system for intraoperative hypotension vs standard care on depth and duration of intraoperative hypotension during elective noncardiac surgery: the HYPE randomized clinical trial. JAMA. 2020;323(11):1052-1060. doi:10.1001/jama.2020.0592

6. Tolone S, Savarino E, Zaninotto G, et al. High-resolution manometry is superior to endoscopy and radiology in assessing and grading sliding hiatal hernia: a comparison with surgical in vivo evaluation. United Eur Gastroenterol J. 2018;6(7):981-989. doi:10.1177/ 2050640618769160

7. Pizza F, D'Antonio D, Lucido FS, et al. Postoperative clinical-endoscopic follow-up for GERD and gastritis after one anastomosis gastric bypass for morbid obesity: how, when, and why. Obes Surg. 2020;30(11):4391-4400. doi:10.1007/s11695-020-04805-9

8. Del Genio G, Tolone S, Gambardella C, et al. Sleeve gastrectomy and anterior fundoplication (D-SLEEVE) prevents gastroesophageal reflux in symptomatic GERD. Obes Surg. 2020;30(5):1642-1652. doi:10.1007/s11695-020-04427-1

9. Srivastava A, Niranjan A. Secrets of safe laparoscopic surgery: anaesthetic and surgical considerations. J Minim Access Surg. 2010;6(4):91-94. doi:10.4103/0972-9941.72593

10. Kazakova T, Hammond B, Talarek C, et al. Anesthetic management for paraesophageal hernia repair. Thorac Surg Clin. 2019;29 (4):447-455. doi:10.1016/j.thorsurg.2019.07.007

11. Kudsi OY, Gokcal F, Bou-Ayash N. Robotic inguinal hernia repair in patients aged eighty and older. Int J Abdom Wall. 2021;4:7-12. doi:10.4103/ijawhs.ijawhs_38_20
12. Wang $\mathrm{Z}$, Chen $\mathrm{G}, \mathrm{Lu} \mathrm{K}$, et al. Investigation of the accuracy of a noninvasive continuous blood pressure device in different age groups and its ability in detecting hypertension and hypotension: an observational study. BMC Anesthesiol. 2019;19(1):223. doi:10.1186/ s12871-019-0899-z

13. Südfeld S, Brechnitz S, Wagner JY, et al. Post-induction hypotension and early intraoperative hypotension associated with general anaesthesia. Br J Anaesth. 2017;119(1):57-64. doi:10.1093/bja/ aex 127

14. Maheshwari K, Turan A, Mao G, et al. The association of hypotension during non-cardiac surgery, before and after skin incision, with postoperative acute kidney injury: a retrospective cohort analysis. Anaesthesia. 2018;73(10):1223-1228. doi:10.1111/anae.14416

15. Brown DR, Fishburne JI, Roberson VO, et al. Ventilatory and blood gas changes during laparoscopy with local anesthesia. Am J Obstet Gynecol. 1976;124(7):741-745. doi:10.1016/S0002-9378(16)33346-4

16. Sharma KC, Kabinoff G, Ducheine Y, et al. Laparoscopic surgery and its potential for medical complications. Heart Lung. 1997;26 (1):52-57. doi:10.1016/S0147-9563(97)90009-1

17. Sessler DI, Khanna AK. Perioperative myocardial injury and the contribution of hypotension. Intensive Care Med. 2018;44 (6):811-822. doi:10.1007/s00134-018-5224-7

18. Sun LY, Wijeysundera DN, Tait GA, et al. Association of intraoperative hypotension with acute kidney injury after elective noncardiac surgery. Anesthesiology. 2015;123(3):515-523. doi:10.1097/ ALN.0000000000000765

19. Czok M, Pluta MP, Putowski Z, et al. Postoperative neurocognitive disorders in cardiac surgery: investigating the role of intraoperative hypotension. A systematic review. Int J Environ Res Public Health. 2021;18(2):786. doi:10.3390/ijerph18020786

20. Mascha EJ, Yang D, Weiss S, et al. Intraoperative mean arterial pressure variability and 30-day mortality in patients having noncardiac surgery. Anesthesiology. 2015;123(1):79-91. doi:10.1097/ ALN.0000000000000686

21. Walsh M, Devereaux PJ, Garg AX, et al. Relationship between intraoperative mean arterial pressure and clinical outcomes after noncardiac surgery: toward an empirical definition of hypotension. Anesthesiology. 2013;119(3):507-515. doi:10.1097/ALN.0b013e31 $82 \mathrm{a} 10 \mathrm{e} 26$
International Journal of General Medicine

\section{Publish your work in this journal}

The International Journal of General Medicine is an international, peer-reviewed open-access journal that focuses on general and internal medicine, pathogenesis, epidemiology, diagnosis, monitoring and treatment protocols. The journal is characterized by the rapid reporting of reviews, original research and clinical studies across all disease areas. The manuscript management system is completely online and includes a very quick and fair peer-review system, which is all easy to use. Visit http://www.dovepress.com/ testimonials.php to read real quotes from published authors. 